\title{
Disruption of type 3 adenylyl cyclase expression in the hypothalamus leads to obesity
}

\author{
Hong Cao ${ }^{1,2}$, Xuanmao Chen ${ }^{2,3}$, Yimei Yang ${ }^{2}$ and Daniel R Storm ${ }^{2 *}$ \\ ${ }^{1}$ Institute of Neurobiology, Institutes of Brain Science and State Key Laboratory of Medical Neurobiology, Fudan University, China \\ ${ }^{2}$ Department of Pharmacology, School of Medicine, University of Washington, USA \\ ${ }^{3}$ Department of Molecular, Cellular, and Biomedical Sciences, University of New Hampshire, USA
}

\begin{abstract}
Evidence from human studies and transgenic mice lacking the type 3 adenylyl cyclase (AC3) indicates that AC3 plays a role in the regulation of body weight. It is unknown in which brain region AC3 exerts such an effect. We examined the role of AC3 in the hypothalamus for body weight control using a floxed AC3 mouse strain. Here, we report that AC3 flox/flox mice became obese after the administration of AAV-CRE-GFP into the hypothalamus. Both male and female AC3 floxed mice showed heavier body weight than AAV-GFP injected control mice. Furthermore, mice with selective ablation of AC3 expression in the ventromedial hypothalamus also showed increased body weight and food consumption. Our results indicated that AC3 in the hypothalamus regulates energy balance.
\end{abstract}

\section{Introduction}

Obesity is a major health issue associated with complications that cause significant morbidity and mortality. Obese individuals have a higher risk for a number of diseases including type 2 diabetes, cardiovascular disease, metabolic syndrome, hypertension, certain forms of cancer, and sleep-breathing disorders [1]. Furthermore, obesity decreases longevity and lowers the general quality of life [2-5]. Although intensive effort has been devoted to anti-obesity therapy, the percentage of obese individuals in industrialized countries continues to increase.

Adenylyl cyclases (ACs) catalyze the synthesis of cyclic 3'5'-AMP (cAMP) from ATP. There are ten AC isoforms that have been cloned and characterized in mammals [6]. It has been reported that AC3 gene polymorphisms are associated with obesity in a group of Swedish men [7]. In another study, a genome-wide association analysis based on height-adjusted BMI found that SNPs in AC3 were associated at genome-wide significance level ( $\mathrm{rs} 11676272(0.28 \mathrm{~kg} / \mathrm{m} 3.1$ change per allele $G(0.19,0.38)$, P56 3 1029). The association signal at AC3 is apparently driven by a miss-sense variant [8]. These human genetic studies suggested that AC3 might play an important role in the regulation of body weight. Previous studies from our lab showed that a global AC3 mouse knockout exhibit adult onset obesity [9]. They show increased fat mass, larger adipocytes, reduced physical activity, increased food consumption, and leptin insensitivity. Subsequently, it was discovered that a gain of function mutation in AC3 protects mice from diet-induced obesity providing further evidence that AC3 may play a major role in weight control [10]. However, why $\mathrm{AC}^{-/}$mice are obese remains unclear.

AC3 is expressed throughout the nervous system and $\mathrm{AC}^{-1-}$ mice exhibit a number of other phenotypes including anosmia, depression, and defects in extinction of hippocampus dependent memory that confound interpretation of the obesity phenotype in the global AC3 knockout. The importance of the hypothalamus in regulating energy balance has been well established [11-13]. For example, ablation of the ventromedial nuclei of the hypothalamus causes overeating and obesity [14]. Since AC3 is expressed in several tissues and various areas of the brain including the hypothalmus, the goal of this project was to determine if $\mathrm{AC} 3$ ablation in the hypothalamus causes adult onset obesity using a floxed AC3 mouse strain.

\section{Methods}

\section{Mice}

Mice were housed at $22-24^{\circ} \mathrm{C}$ with a 12 -h light/dark cycle, and had access to food and water ad libitum. The age of animals used in this study was 2 - 4 months old. AC3 lox/lox mice were generated as previously reported [15]. All animal procedures were approved by the Institutional Animal Care and Use Committee at the University of Washington and performed in accordance with their guidelines.

\section{Body weight and food consumption}

Body weight was monitored before virus injection, then weekly after injection. Food intake was measured daily on the fourth week after virus injection.

\section{Immunofluorescene}

Immunofluorescene procedures were performed as described previously with a few modifications [9]. Mice were perfused with $4 \%$

Correspondence to: Daniel R Storm Ph.D., Department of Pharmacology, HSB J681, University of Washington 1959 NE Pacific St, Seattle, WA 98195 U.S.A, Tel: 1-206-543-9280; E-mail: dstorm@uw.edu

Key words: type 3 adenylyl cyclase, hypothalamus, obesity

Received: April 01, 2016; Accepted: May 10, 2016; Published: May 13, 2016 
paraformaldehyde (PFA). The brains were then dissected and postfixed with the same fixing solution overnight at $4^{\circ} \mathrm{C}$. Then the brains were cryoprotected with $30 \%$ sucrose for $48 \mathrm{hr}$ at $4^{\circ} \mathrm{C}$. Brains were cut into $30 \mathrm{~mm}$ sections with a cryostat freezing microtome. Floating sections were blocked and then first incubated with the AC 3 antibody (1:500, Santa Cruz Biotechnology, Inc.) overnight at $4^{\circ} \mathrm{C}$ followed by the secondary antibody, Alexa Fluor 488-conjugated donkey anti-rabbit IgG (Invitrogen, La Jolla, CA), for $2 \mathrm{hr}$ at room temperature. Stained sections were mounted onto microscopy slides and visualized by confocal microscopy (Zeiss 510 META).

\section{Stereotaxic viral injection}

AAV1-Cre-GFP and AAV1- GFP were bilaterally injected into the hypothalamus $\left(2.2 \times 10^{11}\right.$ viral genome per microliter $)$ of 4 -wk-old AC3 lox/lox mice. According to previous report [16], four-site injections of $0.5 \mu \mathrm{L}$ per site were performed for each side at the coordinates $\mathrm{x}= \pm 0.5$, $\mathrm{y}=-1.4$, and $\mathrm{z}=-5.6$ and -5.0 , which corresponds to ventral and dorsal hypothalamus, respectively. For the VMH injection, two-site injections were performed for each side at the coordinates $\mathrm{x}= \pm 0.5, \mathrm{y}=-1.4$, and $\mathrm{z}=-5.6$. GFP fluorescence was used to identify the virally infected areas. AC3 immunohistochemistry was used to show the expression of AC3. Body weight was monitored before and after virus injection for each mouse. Results from animals that received injections at the correct site as determined by GFP fluorescence were included in analyses.

\section{Statistical analysis}

All data are expressed as means \pm SEM. Data from food consumption were analyzed using the unpaired Student's $t$ test. For body weight curves, the data were analyzed with two-way ANOVA followed by Holm-Sidak Test. $\mathrm{P}<0.05$ was considered to be statistically significant.

\section{Results}

To investigate the role of AC3 in the hypothalamus for regulation of body weight, we injected a recombinant virus AAV-CRE-GFP bilaterally into the hypothalamus of AC3 lox/lox mice, which deletes AC3 expression specifically in the hypothalamus. As showed in Figure 1, AAV-CRE-GFP injected mice showed an obvious weight gain compared to AAV-GFP injected mice 10 weeks later. Both male (Figure 1C) and female (Figure 1D) mice that received the AAV1CRE-GFP construct were significantly heavier than floxed AC3 mice that received an AAV-GFP construct as a control during the period examined (Male, Two way ANOVA, $\mathrm{F}_{(1,170)}=42.67, \mathrm{P}<0.001 \mathrm{~N}=9$ for both groups; Female, Two way ANOVA, $\mathrm{F}_{(1,137)}=54.6123, \mathrm{P}<0.001$; $\mathrm{N}=8$ for GFP control group and $\mathrm{N}=7$ for CRE-GFP group). Adult male floxed AC3 with AAV-CRE-GFP injection are about $20 \%$ heavier that the floxed mice with AAV-GFP injection, while female floxed AC3 mice are $40 \%$ heavier. In addition, the AC3 flox/flox mice with
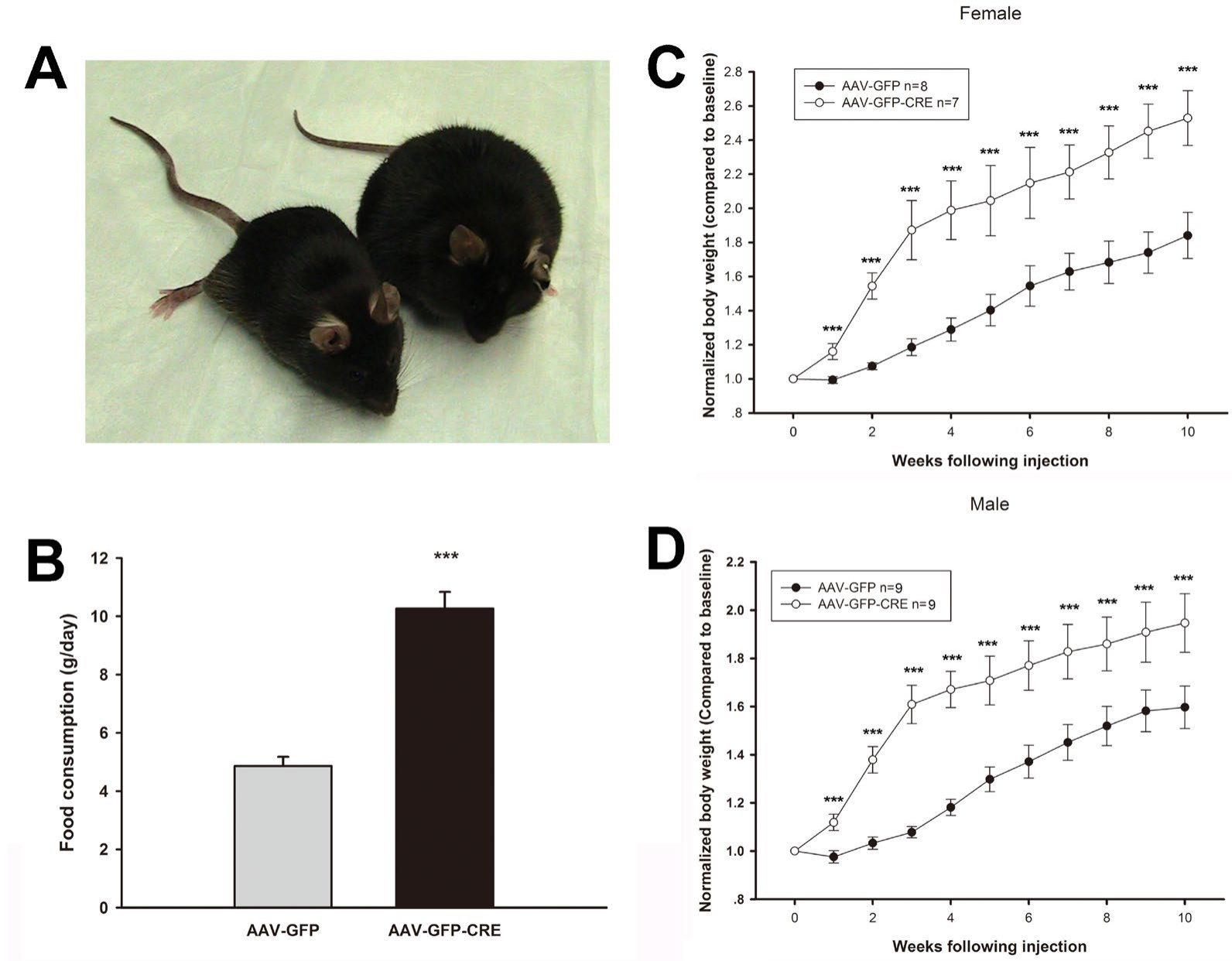

Figure 1. AC3 in the hypothalamus contributes to obesity. A. Representative mice at weeks 10 after AAV-GFP and AAV-GFP-CRE injections. B. Daily food consumption of AC3 lox/lox mice with AAV-GFP and AAV-GFP-CRE injections. C-D.Body weight in female (C), Male (D) mice after introhypothalamus injection of AAV-GFP and AAV-GFP-CRE. 
AAV1-CRE-GFP injection consumed twice as much food daily than the control mice, suggesting that increased food consumption may contribute to the obesity of AC3 floxed mice with AAV-CRE injection. (CRE-GFP vs. GFP (g): $10.26 \pm 0.58$ vs $4.86 \pm 0.31, \mathrm{P}<0.001$ )(Figure 1B). We verified that AC3 expression in the hypothalamus was reduced when AAV1-CRE-GFP was injected into the hypothalamus of floxed AC3 mice using a ployclonal antibody against AC3 (Figure 2).

Several different sites within the hypothalamus are known to be important in regulating body weight including the ventromedial hypothalamic nucleus (VMH). For example, bilateral lesions of the $\mathrm{VMH}$ in rats produced a severe hyperphagic obesity syndrome.
A

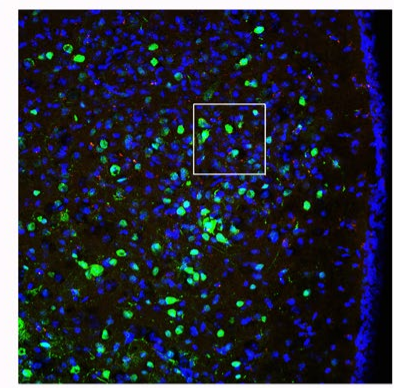

C

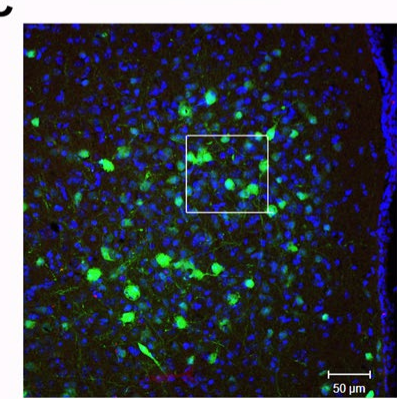

AAV-GFP-CRE 20X
B

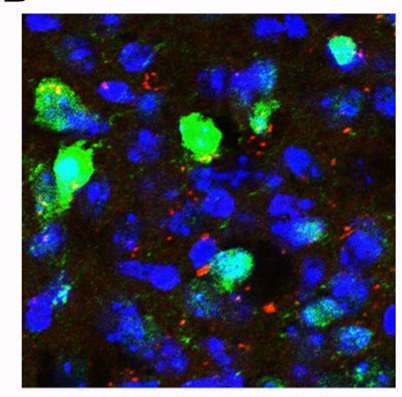

D

DAPI-GFP-AC3

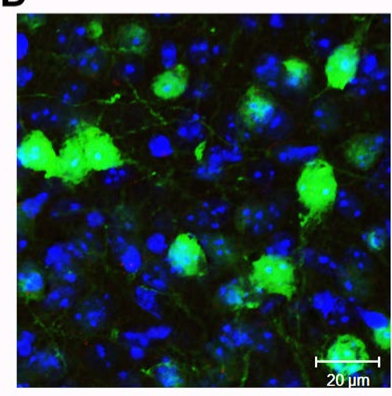

DAPI-GFP-AC3
Figure 2. The immunohisto chemistry showing AC3 (red) expression in the hypothalamus following AAV-GFP injection (A and B) and AAV-GFP-CRE injections (C and D), DAPI (blue), GFP (green) and AC3 (red). Injection site: AP -1.46 mm posterior to Bregma; ML $\pm 0.5 \mathrm{~mm}$; DV -5.0 \& $-5.5 \mathrm{~mm}$.
Therefore, we selectively disrupted AC3 expression in the VMH by injecting AAV1-CRE-GFP to explore whether loss of AC3 in the VMH contributes to obesity (Figure 3). Mice with AAV1-CRE-GFP VMH injection exhibited significant heavier body weight (Two way ANOVA, $\mathrm{F}_{(1,141)}=73.017, \mathrm{P}<0.001, \mathrm{~N}=7$ for control group and $\mathrm{N}=8$ for $\mathrm{AAV}$ CRE-GFP injected group), higher food consumption (CRE-GFP vs GFP, $7.856 \pm 0.718$ vs $5.126 \pm 0.257, \mathrm{P}=0.005)$.

\section{Discussion}

The hypothalamus plays a central role in maintaining energy homeostasis. Different hypothalamic nuclei, including the arcuate nucleus (ARC), dorsomedial hypothalamus (DMH), ventromedial hypothalamus (VMH), paraventricular nucleus (PVN), and lateral hypothalamic area (LH) have been demonstrated to have specific functions in the regulation of energy balance [11-13]. Earlier evidence has reported that lesions in the VMH produced robust increases in adiposity, caused obesity, and in some strains, diabetes [14,17]. In the present study, we found proved that selective ablation of AC3 in the hypothalamus caused obesity. Interestingly, selective ablation of AC3 in the hypothalamus VMH lead to obesity.

It has been reported that AC3 gene polymorphisms are associated with obesity in humans $[7,8]$. We previously reported that disruption of the AC3 gene in mice cause obesity as they aged. Adult male AC3 1- mice are about $40 \%$ heavier than wild type male littermates while female $\mathrm{AC}^{-/}$mice are $70 \%$ heavier. The gain in weight is due to an increase in body fat. Although lipolysis is unaltered in $\mathrm{AC}^{--}$mice, their additional weight is due to leptin insensitivity, increased fat mass and larger adipocytes. Before the onset of obesity, young AC3 ${ }^{1-}$ mice (2 months) exhibit reduced physical activity, increased food consumption, and leptin insensitivity [9]. This suggests that the obesity of $\mathrm{AC}^{-1-}$ may be due to loss of AC3 in the hypothalamus. To address this issue we made a floxed AC3 mouse for the selective disruption of AC3 expression in various areas of the CNS [15].

Selective ablation AC3 expression in AC3 flox/flox mice using VMH-injection of AAV-CRE-GFP significantly increased the body weight, supporting the hypothesis that $\mathrm{AC} 3$ in the ventromedial hypothalamus plays an important role in control of weight. A possible contributor to obesity caused by AC3 ablation is leptin insensitivity. Leptin can act in the hypothalamus to reduce food intake and increase
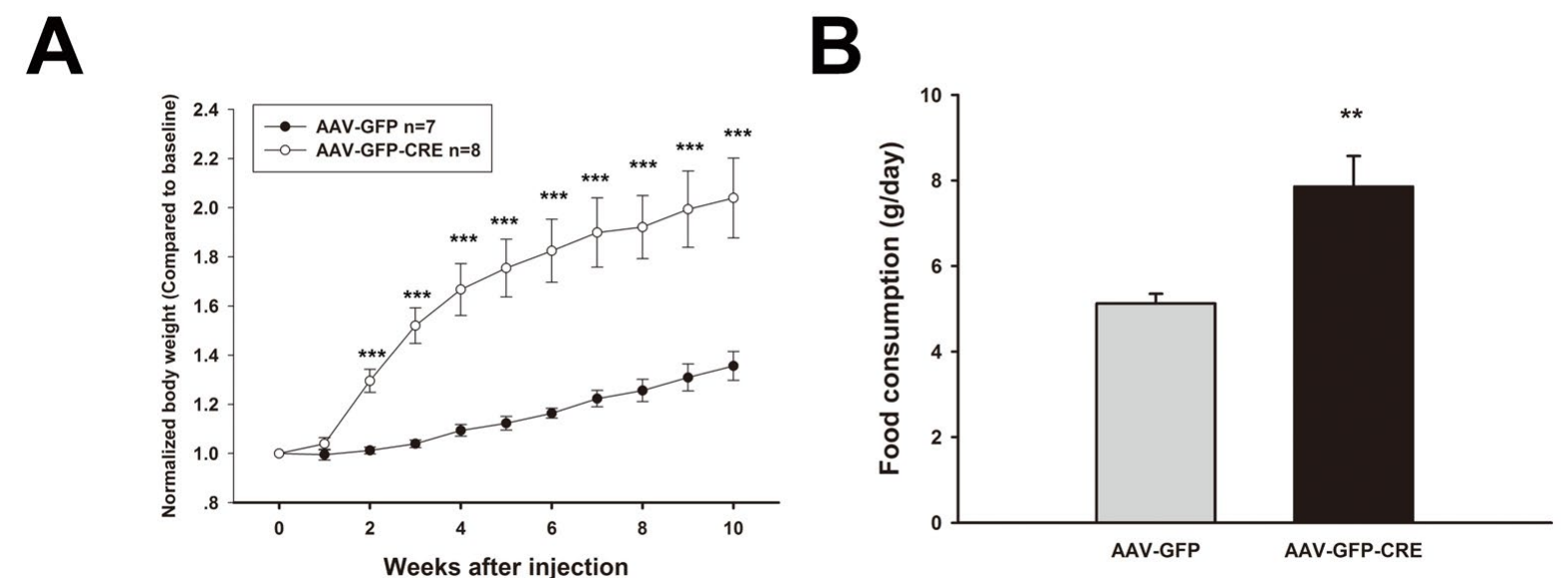

Figure 3. The mice with specific ventromedial hypothalamus injection of AAV-GFP-CRE develop obesity. A. The body weight of AC3 lox/lox mice with VMH injection of AAV-GFP and AAV-GFP-CRE respectively. B. Daily food consumption of AC3 lox/lox mice after AAV-GFP and AAV-GFP-CRE injections. 
physical activity [18]. The leptin receptor is a JAK-STAT receptor and it is not directly coupled to adenylyl cyclase activity. The role of AC3 in leptin insensitivity is therefore likely to be downstream of the leptin receptors in the ventromedial hypothalamus. It has been reported that the VMH mediates the leptin-induced increase in glucose utilization as well as its insulin sensitivity in the whole body through activation of the melanocortin receptor (MCR). Leptin sensitivity is due, in part, to production of alpha-MSH which stimulates adenylyl cyclase activity in MC4-R-expressing neurons in the ventromedial hypothalamus [19]. POMC neurons originating in the arcuate nucleus contact synaptically at MC4-R containing neurons in the VMH or other hypothalamic nuclei that participate in control of feeding behavior [19]. The importance of MC4-Rs in control of body weight is illustrated by the presence of extreme obesity in MC4-R gene knockout mice and in humans with mutations in MC4-R [20,21]. Furthermore, the injection of agonists of the MC4-R ICV into mice significantly depresses food consumption while chronic blockade of MC4-R causes obesity [22]. Since AC3 is one of the major adenylyl cyclases expressed in the hypothalamus and $\mathrm{AC}^{--}$mice exhibit obesity, it is possible that MC4-R receptors normally couple to stimulation of AC3 in neurons of the VMH to generate cAMP signals which lead to appetite suppression and/or energy utilization. Hence, the obesity of AC3 flox/flox mice after AAV-CRE-GFP administration may be due to loss of cAMP production in $\mathrm{VMH}$ neurons in response to melanocortins, thereby leading to obesity. Taken together, our results indicated that $\mathrm{AC} 3$ might be a potential drug target site to combat obesity.

\section{Acknowledgements}

This work was supported by National Natural Science Fund of China (NSFC 30425022), China Postdoctoral Science Foundation (2014M551317) and the International Postdoctoral Exchange Fellowship Program 2013 (201355). This study was also funded by NIH grants DC004156 and MH073601 to D.R.S., MH105746 to X.C.

\section{References}

1. Kopelman PG (2000) Obesity as a medical problem. Nature 404: 635-643. [Crossref]

2. Bray GA (2006) Obesity: the disease. J Med Chem 49: 4001-4007. [Crossref]

3. Fontaine KR, Redden DT, Wang C, Westfall AO, Allison DB (2003) Years of life lost due to obesity. JAMA 289: 187-193. [Crossref]

4. Spiegelman BM1, Flier JS (2001) Obesity and the regulation of energy balance. Cell 104: 531-543. [Crossref]

5. Fontaine KR, Barofsky I (2001) Obesity and health-related quality of life. Obes Rev 2: 173-182. [Crossref]
6. Hanoune J, Defer N (2001) Regulation and role of adenylyl cyclase isoforms. Annu Rev Pharmacol Toxicol 41: 145-174. [Crossref]

7. Nordman S1, Abulaiti A, Hilding A, Långberg EC, Humphreys K, et al. (2008) Genetic variation of the adenylyl cyclase 3 (AC3) locus and its influence on type 2 diabetes and obesity susceptibility in Swedish men. Int J Obes (Lond) 32: 407-412. [Crossref]

8. Stergiakouli E, Gaillard R, Tavaré JM, Balthasar N, Loos RJ, et al. (2014) Genomewide association study of height-adjusted BMI in childhood identifies functional variant in ADCY3. Obesity (Silver Spring), 22: 2252-2259. [Crossref]

9. Wang Z, Li V, Chan GC, Phan T, Nudelman AS, et al. (2009) Adult type 3 adenylyl cyclase-deficient mice are obese. PLoS One 4: e6979. [Crossref]

10. Pitman JL, Wheeler MC, Lloyd DJ, Walker JR, Glynne RJ, et al. (2014) A gain-offunction mutation in adenylate cyclase 3 protects mice from diet-induced obesity. PLoS One 9: e110226. [Crossref]

11. Elmquist JK, Elias CF, Saper CB (1999) From lesions to leptin: hypothalamic control of food intake and body weight. Neuron 22: 221-232. [Crossref]

12. Schwartz MW, Woods SC, Porte D Jr, Seeley RJ, Baskin DG (2000) Central nervous system control of food intake. Nature 404: 661-671. [Crossref]

13. Spiegelman BM, Flier JS (2001) Obesity and the regulation of energy balance. Cell 104: 531-543. [Crossref]

14. Brobeck JR (1946) Mechanism of the development of obesity in animals with hypothalamic lesions. Physiol Rev 26: 541-559. [Crossref]

15. Chen X, Luo J,LengthY, YangY, Zweifel LS, et al. (2016) Alation of Type III Adenylyl cyclase in mice causes reduced neuronl activity, altered sleep pattern, and depressionlike phenotypes. Biological Psychiatry In Press. [Crossref]

16. Zheng R, Yang L, Sikorski MA, Enns LC, Czyzyk TA, et al. (2013) Deficiency of the RIII ${ }^{2}$ subunit of PKA affects locomotor activity and energy homeostasis in distinct neuronal populations. Proc Natl Acad Sci U S A 110: E1631-1640. [Crossref]

17. Bray GA (1984) Hypothalamic and genetic obesity: an appraisal of the autonomic hypothesis and the endocrine hypothesis. Int J Obes 8 Suppl 1: 119-137. [Crossref]

18. Pandit R, de Jong JW, Vanderschuren LJ, Adan RA (2011) Neurobiology of overeating and obesity: the role of melanocortins and beyond. Eur J Pharmacol 660: 28-42. [Crossref]

19. Toda C, Shiuchi T, Kageyama H, Okamoto S, Coutinho EA et al. (2013) Extracellular Signal-Regulated Kinase in the Ventromedial Hypothalamus Mediates Leptin-Induced Glucose Uptake in Red-Type Skeletal Muscle. Diabetes 62: 2295-2307. [Crossref]

20. Huszar D, Lynch CA, Fairchild-Huntress V, Dunmore JH, Fang Q, et al. (1997) Targeted disruption of the melanocortin-4 receptor results in obesity in mice. Cell 88 : 131-141. [Crossref]

21. Vaisse C, Clement K, Guy-Grand B, Froguel P (1998) A frameshift mutation in human MC4R is associated with a dominant form of obesity. Nat Genet 20: 113-114. [Crossref]

22. Fan W, Boston BA, Kesterson RA, Hruby VJ, Cone RD (1997) Role of melanocortinergic neurons in feeding and the agouti obesity syndrome. Nature 385: 165-168. [Crossref]

23. Vergoni AV, Bertolini A, Guidetti G, Karefilakis V, Filaferro M, et al. (2000) Chronic melanocortin 4 receptor blockage causes obesity without influencing sexual behavior in male rats. J Endocrinol 166: 419-426. [Crossref]

Copyright: (C2016 Cao H. This is an open-access article distributed under the terms of the Creative Commons Attribution License, which permits unrestricted use, distribution, and reproduction in any medium, provided the original author and source are credited. 